\title{
Un escarabeo egipcio procedente de Mallorca
}

\section{An egyptian scarab from Mallorca}

\author{
JOSEP PADRÓ
}

Secció de Prehistòria i Arqueologia. Departament d'Història i Arqueologia Facultat d'Història. Universitat de Barcelona

C/ Montalegre, 6, E-08001, Barcelona

jpadro@ub.edu

De Mallorca procede un escarabeo; la única pieza egipcia que, con cierta seguridad, podemos afirmar que procede de la isla. La pieza habría sido hallada, junto a otros materiales arqueológicos, hace ya años por un aficionado en una cueva de enterramiento del Talayótico final, y fue mostrada al padre Cristòfor Veny en el Santuari de Lluc, quien tuvo ocasión de fotografiarla y de comunicarme el hallazgo. Su paradero actual es desconocido. La inscripción de su reverso puede interpretarse ideográficamente como la adoración de los simios ante la salida del Sol, Re. Quizá también, aunque con dudas, podría ser leída criptográficamente como un «trigrama de Amón».

\section{PALABRAS CLAVE}

MALLORCA, ESCARABEO EGIPCIO, CUEVA SEPULCRAL, SIMIOS, SOL/RE, "TRIGRAMA DE AMÓN»

Presented here, from Mallorca, is a scarab, the only Egyptian artefact which we know for certain to have been found on the island. The piece was found, together with other archaeological material, many years ago by an enthusiast in a burial cave of the Late Talayotic period. It was shown to Padre Cristòfor Veny in the Santuari de Lluc, who took the opportunity to photograph it and tell me about its existence. Its present day location is not known. The inscription on the back may be interpreted as an ideogram for the adoration by the monkeys of the rising of the Sun, the god Re. Perhaps also, though with some doubts, it could be read cryptographically as a 'Trigram of Amon'.

\section{KEY WORDS}

MALLORCA, SCARAB, EGYPTIAN, BURIAL CAVE, MONKEYS, SUN/RE, 'TRIGRAM OF AMON' 
Estos últimos años se han producido algunas novedades sobre la aparición de objetos de tipo egipcio en Occidente, de las cuales he tenido noticia. ${ }^{l}$ Una de las más interesantes es la que se refiere al hallazgo de escarabeos en la necrópolis navarra de El Castillo, en Castejón (Faro, Cañada y Unzu, 2002-2003: 73). Poco más se puede decir, de todos modos, de este hallazgo, excepto que probablemente se trata de escarabeos pseudoegipcios y que, en todo caso, demuestra la profunda penetración del comercio mediterráneo remontando el valle del Ebro. Junto a la desembocadura del Ebro y en su margen izquierda, en el yacimiento de La Palma, ya conocido por el descubrimiento de la necrópolis paleoibérica del Mas de Mussols, con sus escarabeos y escaraboide, Jaume Noguera está excavando un campamento romano de la Segunda Guerra Púnica, donde ha sido hallado un escarabeo de bronce que completa, un poco, el huidizo panorama de los aegyptiaca del siglo III aC en la península Ibérica. ${ }^{2}$

Hace unos años tuve ocasión de revisar y poner al día la problemática de los hallazgos de tipo egipcio en la península Ibérica (Padró, 1995; 2008: 28-33 y 384), de modo que tampoco voy a insistir sobre ello, salvo para mencionar el muy interesante catálogo de una exposición que tuvo lugar en Alicante (Olcina y Ramón, 2010). Más recientemente, la problemática de los numerosos hallazgos de escarabeos en Ibiza ha sido puesta al día (Padró, 2014: 517-520; Velázquez, López-Grande, Mezquida y Fernández, 2015), y un nuevo escarabeo ha sido documentado en el Languedoc, en el yacimiento de Lattes (Padró, 2010: 757-758).

De entre todos estos novedosos hallazgos queda por reseñar el de un escarabeo egipcio procedente de la isla de Mallorca, sin que se pueda determinar ni su lugar de origen ni su contexto, ${ }^{3}$ solo apuntar quizás una cueva del Talayótico tardío en el entorno del Santuari de Lluc (Escorca, Mallorca).

El escarabeo está engarzado en oro y había formado parte de un anillo de hierro. Según el padre Veny la pieza es de hueso. Mide 18 x $11 \mathrm{~mm}$. El anverso presenta una

1. Mi amistad con el profesor José Luis Maya me llevó a querer participar en el estudio de uno de estos objetos en un volumen de homenaje que debía dedicársele y publicarse en 2010, casi a los diez años de su fallecimiento en 2001. Pero, pasados los años, este homenaje no ha llegado a ver la luz, de modo que he decidido publicar dicho estudio en la revista Pyrenae, de la Universidad de Barcelona, donde el Prof. Maya ejerció la docencia los últimos años de su vida.

2. Doy las gracias al excavador por esta información, y por haberme mostrado tan singular pieza.

3. Agradezco al padre Cristòfor Veny, ilustre prehistoriador fallecido en 2007, aunque sea póstumamente, su confianza en mí y el haberme facilitado la información y el material fotográfico que después ha sido preparado por R. Àlvarez. En 2001 contactó conmigo y mostró las fotografías de este hallazgo. Según la información del padre Veny, en carta de 26 de enero de 2001, hacía ya unos años que un grupo de jóvenes aficionados al montañismo le mostraron, en el Santuari de Lluc, materiales arqueológicos procedentes de una cueva de enterramiento del Talayótico final, entre los que había cal, huesos quemados, ajuar típico de bronce y hierro, etc., así como el escarabeo en cuestión. Según parece, la cueva había sido revuelta por el padre de uno de ellos muchos años antes, pero los jóvenes o no quisieron o no supieron dar el nombre de la cueva al padre Veny. Este pensó que quizá con el tiempo lo averiguaría, pero aparentemente ya no tuvo ocasión. Pusieron a su disposición la pieza y así pudo fotografiarla, examinarla y medirla. 


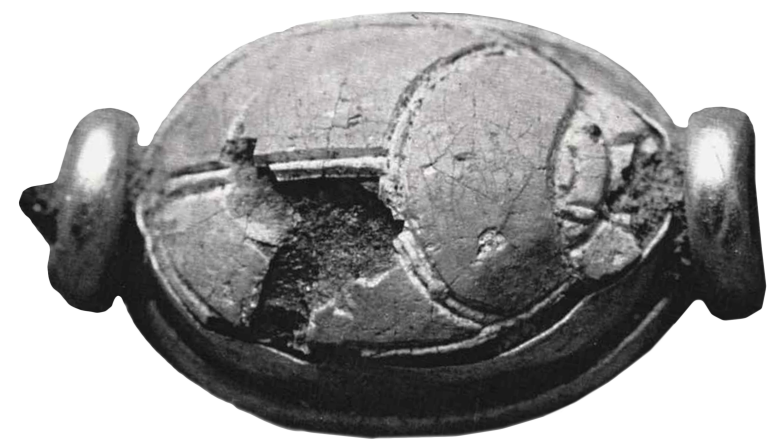

Figura 1. Anverso y reverso del escarabeo egipcio de Mallorca (fotos de Cristòfor Veny cedidas al autor, preparadas por R. Àlvarez).

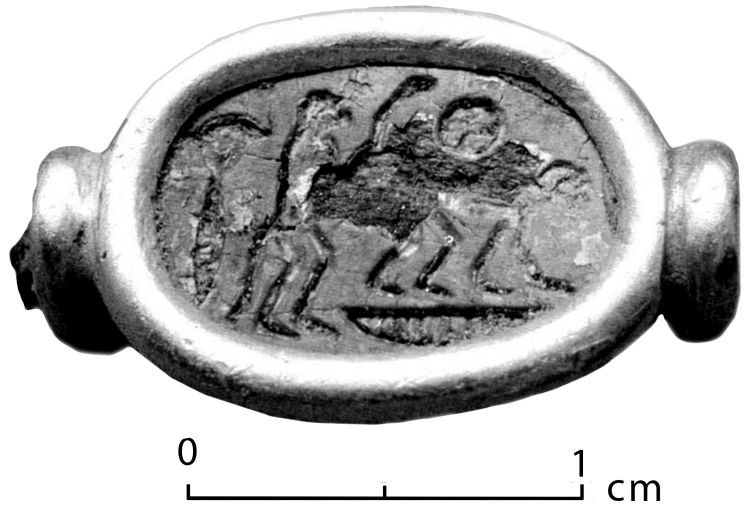

profunda rotura, que no impide apreciar que los rasgos del animal están bien trazados, con el clípeo, el protórax y los élitros bien definidos y dibujados con una doble línea: su esquema dorsal pertenece, en suma, al tipo IV b (Padró, 1980: 55, lám. XXV, 1) (fig. 1).

No hemos podido ver la pieza original, de modo que la descripción de su reverso se basa exclusivamente en la fotografía, así como en la descripción del mismo padre Veny. Se trata de una escena muy original, para la que no hemos sabido encontrar paralelos. A pesar de un desperfecto en la superficie, podemos apreciar suficientemente los detalles. De derecha a izquierda vemos, arriba, un disco solar; en medio, un simio andando a cuatro patas con la cola levantada, mirando a la derecha y, debajo, un cesto. Detrás de estos tres signos vemos otro simio en pie, mirando también a la derecha, con la cola caída y presumiblemente con los brazos proyectados hacia delante, en actitud de adoración; la duda viene de que esta parte está deteriorada. Finalmente, y detrás del segundo simio, hay un tallo de papiro. Añadamos que el primer simio corresponde al signo E33 de Gardiner, definido como «mono» (Gardiner, 1957: 461; Padró, 2007: 226), mientras que el segundo es el signo F62 1 de la lista de valores fonéticos de Daumas (Daumas et al., vol. I, 1988: 248).

Creo que esta representación debe interpretarse como expresión de la adoración de los simios ante la salida del sol; según Vernus en su artículo sobre los simios (Vernus y 
Yoyotte, 2005: 615-627), estos son —entre otras cosas— particularmente activos durante la salida del sol; multiplican gesticulaciones, gritos y chillidos, agitación tanto más remarcable en tanto que viven en copiosas bandas, de docenas o centenares de individuos. Los egipcios veían en ello manifestaciones de homenaje a la divinidad solar: «Los simios se activan para ti con sus brazos. Cantan para ti, danzan para ti, te glorifican con su boca, te anuncian tanto en el cielo como en la tierra». Frecuentemente agrupados por pares, sentados, erguidos o a cuatro patas, acompañan las diversas manifestaciones del astro, y sobre todo su salida matinal (Vernus e Yoyotte, 2005: 625).

Este es, a mi juicio y a falta de mejor explicación, el simbolismo de la representación del reverso del escarabeo de Mallorca: la agrupación de dos simios en una misma escena y junto al disco solar no parece ofrecer margen de duda; en actitudes diferentes, ambos están saludando la salida del sol. En cuanto a la planta de papiro, con su significado de «reverdecer», no hace sino reforzar esta misma idea: la reapertura del cáliz de las plantas cada amanecer. El signo del cesto tendría su habitual significado de "señor». De hecho, he pensado también en la posibilidad de que estemos ante un «trigrama de Amón» (Drioton, 1957: 11-33), pero la dificultad de interpretación correcta de algún signo hace que prefiera la primera explicación.

La técnica de la talla de la escena es muy simple, pero expresiva, y permite fácilmente identificar los signos que la componen. La fabricación del escarabeo es, pues, egipcia con toda seguridad. Otra cosa es la fecha. El padre Veny fechó el posible contexto, según otros materiales del yacimiento, en época tardía, entre los siglos III y i aC. Por mi parte, no me queda sino añadir que, ante la ausencia de paralelos, me resulta imposible atribuir una fecha de fabricación mínimamente aproximada a este escarabeo. Mi objetivo, pues, no ha sido otro que el de dar a conocer esta interesante pieza, la primera hallada en Mallorca, y quedar a la espera de nuevos ejemplares que puedan ilustrar la interpretación aquí ofrecida a modo de hipótesis.

\section{Bibliografía}

DAUMAS, F. (ed.), 1988, Valeurs phonétiques des signes hiéroglyphiques d'époque gréco-romaine, vol. 1, Montpellier.

DRIOTON, É., 1957, Trigrammes d'Amon, Wiener Zeitschrift für die Kunde des Morgenlandes 54, Festschrift Hermann Junker, Viena, 11-33.

FARO CARBALLA, J. A., CAÑADA PALACIO, F. y UNZU URMENETA, M., 2002-2003, Necrópolis de El Castillo (Castejón, Navarra). Primeras valoraciones, Campañas 2000, 2001, 2002, Trabajos de Arqueología de Navarra 16, 45-77. GARDINER, A., 1957, Egyptian Grammar, Oxford (3. ${ }^{\mathrm{a}}$ ed.).

OLCINA DOMÈNECH, M. H. Y RAMÓN SÁNCHEZ, J. J. (eds.), 2010, Objetos egipcios en Alicante, Alicante. 
PADRÓ i PARCERISA, J., 1980, Egyptian-type Documents from the Mediterranean Littoral of the Iberian Peninsula, before the Roman Conquest, Études Préliminaries aux Religions Orientales dans l'Empire Romain, t. 65, vol. I, Leiden.

PADRÓ i PARCERISA, J., 1995, New Egyptiantype Documents from the Mediterranean Littoral of the Iberian Peninsula before the Roman Conquest, Orientalia Monspeliensia, VIII, Montpellier.

PADRÓ, J., 2007, La lengua de Sinuhé. Gramática del Egipcio Clásico, Barcelona.

PADRÓ, J., 2008, Egipto, el Mar Mediterráneo y la Península Ibérica en la Antigüedad, en F. GODDIO (ed.), Tesoros sumergidos de Egipto, Madrid, Múnich, Berlín, Londres, Nueva York, $28-33$ y 384.
PADRÓ, J., 2010, Un scarabée punique découvert à Lattes, en T. JANIN (ed.), Lattara, 21. Premières données sur le cinquième siècle avant notre ère dans la ville de Lattara, t. 2, Lattes, 757-758.

PADRÓ, J., 2014, Escarabeus d'Eivissa de la Col-lecció Lluís Llobet, en In Amicitia. Miscel-lània d'estudis en homenatge a Jordi H. Fernández, Treballs del Museu Arqueològic d'Eivissa i Formentera, 72, Ibiza, 517-521.

VELÁZQUEZ, F., LÓPEZ-GRANDE, M. J., MEZQUIDA, A. y FERNÁNDEZ, J., 2015, Nuevos estudios sobre escarabeos hallados en Ibiza, Treballs del Museu Arqueològic d'Eivissa i Formentera, 73, Ibiza.

VERNUS, P. e YOYOTTE, J., 2005, Bestiaire des Pharaons, París. 
